\title{
New Analysis Theory and Method for Drag and Torque Based on Full-Hole System Dynamics in Highly Deviated Well
}

\author{
Xiao-hua Zhu, ${ }^{1}$ Bo Li, ${ }^{1}$ Qing-you Liu, ${ }^{1}$ Xue-jun Chang, ${ }^{2}$ Liang-chuan Li, ${ }^{2}$ \\ Kuan-liang $\mathrm{Zhu},{ }^{2}$ and $\mathrm{Xiao}$-feng $\mathrm{Xu}^{2}$ \\ ${ }^{1}$ College of Mechatronic Engineering, Southwest Petroleum University, Chengdu 610500, China \\ ${ }^{2}$ PetroChina Jidong Oilfield Company, Tangshan 063004, China \\ Correspondence should be addressed to Xiao-hua Zhu; zxhth113@163.com
}

Received 11 September 2014; Accepted 15 December 2014

Academic Editor: Chenfeng Li

Copyright (C) 2015 Xiao-hua Zhu et al. This is an open access article distributed under the Creative Commons Attribution License, which permits unrestricted use, distribution, and reproduction in any medium, provided the original work is properly cited.

The research on calculation of torque and drag in highly deviated wells has demonstrated a significant gap against oil exploration and development; with the increasingly rigorous situation, the drill string dynamics and the contact or friction of drill pipe with borehole wall under the drill string action of dynamic need more attention and urgent research work. Based on full-hole system dynamics, three-dimensional nonlinear dynamic model and dynamic torque and drag model were established in highly deviated well by using the finite element method. An application of analyzing typical torque and drag problems presented here provides a means to more accurate description of the contact relation between drill string and wellbore. The results show that those models established in this paper have complete adaptability for a complex three-dimensional borehole trajectory. For the actual well application, it will help to evaluate security performance of drill string in complex working conditions.

\section{Introduction}

With scarcity of resources, great difficulties have been confronted with oil companies during the process of exploration drilling of oil or gas and the complexity of drilling geological environment is now bottlenecking the development of drilling technology. Due to the geographical conditions, most oil and gas wellbore trajectories have to be catenary curve which is used to substitute for straight line; well profiles have to adopt highly deviated well [1]. In recent years, the reach of highly deviated wells has increased; it provides a larger producing low porosity and low permeability reservoir. With highly deviated well drilling, the construction is quite difficult which is often caused by designed path and has a great deviation angle. Frequent contact-rubbing between bending drill string and borehole wall has developed great friction; it put forward the higher requirements of drilling equipment. At the same time, it influences the transmission of drilling string axial load; its major expression is as follows: this substantially increases the drag on the borehole walls; control of the well trajectory becomes more difficult, reducing weight and torque which are applied to the bit; then drilling rate always is decreased. Cuttings bed is formed easily in long open hole interval, which is not obvious under normal inspection and can be difficult to clear up; sometimes there are failure accidents of the drilling equipment in this situation. It is difficult to guarantee the cementing quantity because it may not easily make the casing centralized in wellbore and runs casing in.

In brief, the above-mentioned problems commonly exist in highly deviated wells; on the basis of torque and drag modeling originally started by the works of Johancsik et al. [2], researchers at home and abroad have been improving theoretical basis provided for analyzing and forecasting the frictional resistance and excellent effects are obtained. In 1984, Johancsik et al. [2] assumed that both torque and drag are caused entirely by sliding friction forces that result from contact of the drill string with the wellbore. They then define the sliding friction force to be a function of the normal contact force and the coefficient of friction between the contact surfaces based on Coulomb's friction model. They wrote the force balance for an element of the pipe 
considering that the normal component of the tensile force was acting on the element contributing to the normal force. The relationship between the helical buckling of a drill string and torque is discussed by He and Kyllingstad [3]; Maidla and Wojtanowicz [4] presented a method to evaluate an overall friction coefficient between the wellbore and the casing string, assuming that a friction coefficient matches field data and modeling; the equation for predicting surface hook loads is derived from the respective governing differential equations. Schamp et al. [5] suggested some industrial methods to reduce torque in the wellbore during drilling. Mason and Chen [6] pointed out that the change of borehole curvature would affect torque and drag values on a large scale. In 1993, two-dimensional model and three-dimensional model for calculating the friction 8 analyses were established by professor Han [7]. Gao [8, 9] put forward a new calculation model by applying weighted residual method. Shuai et al. [10] analyzed drag and torque by finite element method, and then, on the drilling string system dynamics, professor Zhu [11-13] established a new method of calculation of torque and drag.

Overall, the research on calculation of torque and drag should be deeper and wider in highly deviated wells, resulting in a lot of errors in the torque and drag parameters computed, which has demonstrated a significant gap against oil exploration and development with the increasingly rigorous situation, so the drill string dynamics and the contact or friction of drill pipe with borehole wall under the drill string action of dynamic need more attention and urgent research work, its purposes are to study the drill string vibration rules and the reasons of drill string failure in highly deviated wells, especially to understand the law of torque and drag and promote the development of new drilling technologies in special technology. Therefore, this paper established the models for vertical, lateral, and torsion coupled vibration of full-hole drilling strings in highly deviated well with mud drilling using the finite element method to dynamically analyze torque and drag of string drilling in operation.

\section{Model Description}

The new model has been developed based on full-hole system dynamics, in which the finite element method is used to model the drill string used in rotational drilling operations. The ABAQUS FEM Explicit solver package was used to develop the dynamic FEM model [14]. In this section, more equations of full-hole system dynamics would be present, but the formulation of equations of motion proceeds along the same lines of the model in [15], So final forms of equations are included here for completeness, without many details.

2.1. Hypotheses. Before establishing the model, the following main assumptions would be needed with synthesizing structure characteristics of full-hole drilling strings, boundary constrains, and load conditions, based on the theory of nonlinear transient:

(1) the drill string is simplified to homogeneous beam; cross section shape is circle, ignoring threaded connections between the drill string and partially perforated structures; the geometric size of the drill string and material properties of the drill string can be segmented or grouped depending on drilling tools assembly without considering the impact of temperature;

(2) keep the rotation speed constant at the top of the drill string;

(3) rock fragmentation process in real time is used for the boundary condition of the end of the drill string, because strength and hardness of bit is greater than that of bottom rock, so set bit to a rigid body in the analysis; rock is assumed to be an isotropic material and rock nonlinearity is simulated by DP elasticplastic model; simply using finite element method removes the failure elements from rock elements and ignores its influence on subsequent drilling;

(4) borehole wall has large rigidity; its cross section is usually in a circular form; its axis is a smooth curve in three-dimensional space with continuous second order derivatives which was made as interpolation to the measured well inclination data.

2.2. Dynamic Finite Element Model of the Drilling. Accordingly, one needs to write the kinetic and strain energy expressions. In this context, the kinetic energy can be expressed in the form as [15]

$$
\begin{aligned}
T= & \frac{1}{2} \dot{e}^{\mathrm{T}} M_{t} \dot{e}+\frac{1}{2} I \dot{\Omega}^{2}+\frac{1}{2} \dot{e}^{\mathrm{T}} M_{\varphi} \dot{e}-\dot{e} \dot{\Omega}^{\mathrm{T}} \\
& -\dot{e}^{\mathrm{T}} M_{e} \dot{e}+\frac{1}{2} \dot{e}^{\mathrm{T}} M_{r} \dot{e} \\
= & \frac{1}{2} \dot{e}^{\mathrm{T}} M \dot{e}+\frac{1}{2} I \dot{\Omega}^{2}-\dot{\Omega} \dot{e} \dot{e}^{\mathrm{T}} C \dot{e},
\end{aligned}
$$

where $M=M_{t}+M_{r}+M_{\varphi}-2 M_{e}$ is the augmented mass matrix with the constituent matrices given by $M_{t}$ which is the translational mass matrix, $M_{r}$ is the rotary inertia mass matrix, $M_{\varphi}$ is the torsional mass matrix, and $M_{e}$ is the torsional-transverse inertia coupling mass matrix, which is time dependent. The matrix $I$ is the damping matrix, and $\Omega$ is the constant angular velocity of the rotary table. In this formulation, $e$ is the vector of nodal coordinates of the twonode finite string element.

The total strain energy can be written in compact matrix form as

$$
U=\frac{1}{2} e^{\mathrm{T}} K e
$$

where $K$ is the augmented stiffness matrix.

Based on the Hamilton theory [16], by utilizing the above energy expressions into the vibrational form of Lagrange's equation, full well system dynamics equation is obtained as

$$
[M]\{\ddot{\mu}\}+[I]-[P]=0,
$$

where $[M]$ is the mass matrix, $[I]=[C]\{\dot{\mu}\}+[K]\{\mu\}$ is the viscous term, considering damping, sticky plastic and 


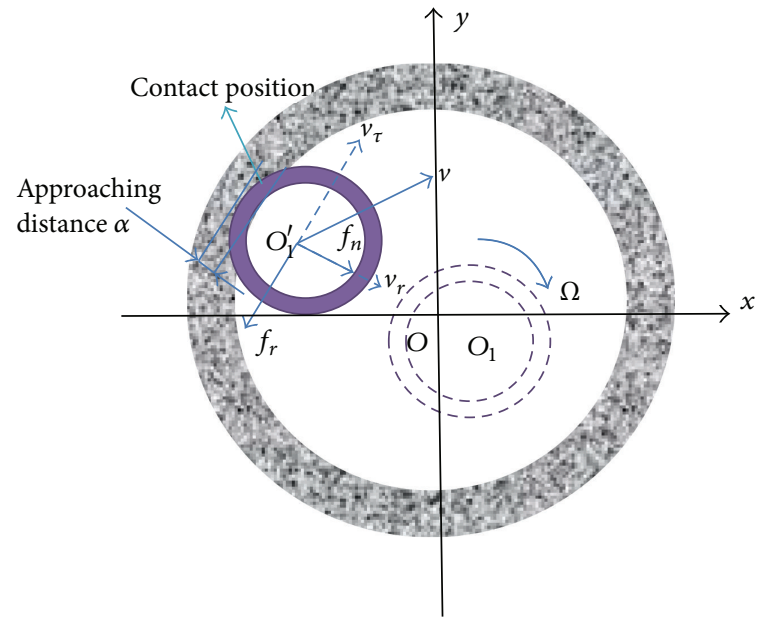

(a)

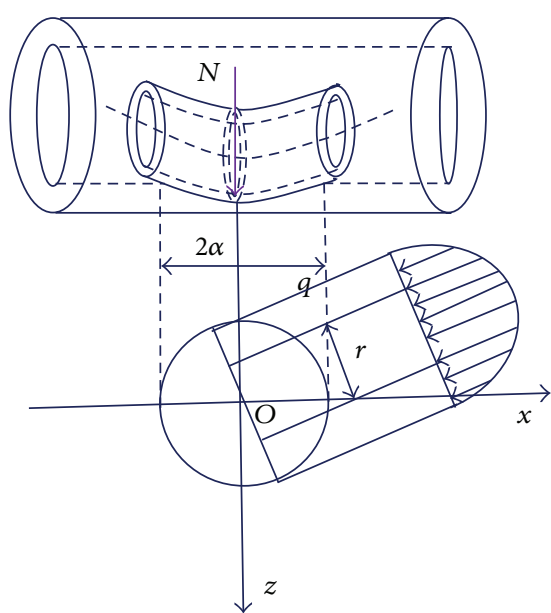

(b)

FIGURE 1: Drill pipe-wellbore contact model: (a) the contact between drill string and borehole wall and (b) the contact interface formed by the drill string and borehole wall.

viscoelastic effect, $[C]$ is the damping matrix, $[K]$ is the stiffness matrix, $[P]$ is the function of external excitation, and $\{\mu\},\{\dot{\mu}\},\{\ddot{\mu}\}$ are the node displacement, velocity, and acceleration vector.

The following boundary conditions are considered. As a result of the limitation of wheel to drill string in well hole, wellhead node lateral displacement and lateral rotation angle are zero, correcting wellhead node generalized displacement in real time, keeping lateral force the same. Twisting vibration is thought to exist when dealing with the drill string twist boundary, but only mainly in lower parts of drill string. For the top node of the drill string, because of the constant power drilling rig, we assume that rotating speed of the top node is constant, but its torque is fluctuating. Axial displacement of the top node is not fixed, and a lift force is joined on it to simulate the hook load:

$$
\begin{aligned}
& \mu_{x=0, t}=0, \\
& \mu_{y=0, t}=0, \\
& \theta_{x=0, t}=0, \\
& \theta_{y=0, t}=0, \\
& \omega_{z=0, t}=\Omega .
\end{aligned}
$$

Based on the interaction of bit and formation, the force from the rock and bit is used for the boundary condition of the end of the drill string. Considering the coupled relations between the drill string and the bit, both of them are linked into a whole unit to make rock failure and drilling hole without constraints of any degrees of freedom. The formation of the hole is relative to the lower longitudinal vibration of drill string and interaction between bit and formation. The drill bit is a direct tool for rock breakage; the longitudinal impact allows it into the bottom hole rock layer and small pieces of the rock that deform and break away due to the lateral scraping action of the bit teeth. Then cuttings are washed from the bottom by drilling fluid.

2.3. Contact Algorithm. Rotating drill string movement along the cross section of the wellbore is hedged about with wellbore wall, when the outer wall of the drill string is closing to borehole wall, and the drill string has a trend of move outwards; then the drill string will collide with the wall with rubbing contact. The contact and friction of a drill pipe string with borehole wall have become the basic research of the drill string dynamics and drag and torque calculation, whose effect on the dynamic characteristics of drill string cannot be ignored, and it is difficult to analyze.

The contact between drill string and borehole wall in the process of highly deviated well drilling is of large area and geometrically nonlinear with unpredictability; this can be seen from the following: inability to forecast the points of contact between borehole wall and drill string, influenced by torsional vibration and axial vibration of drill string, and the value of the impact force and the contact time along the contact position. Even with using the same drilling assembly, the contact position and the value of the contact force are also not the same under different real well trajectory or drilling conditions. So this paper introduces stochastic boundary method for prediction of contact stress.

The annular tolerance between drill string and borehole wall can be used to judge whether the drill string and borehole wall contact in a calculation. Drill string is in a state of freedom of movement without contacting the borehole wall; there is no constraint reaction force. When the drill string connects with borehole wall as shown in Figure 1, the motion of drill string is handicapped in its operation providing a certain amount of normal force $N$, the axial frictional force $f_{\tau}$, the tangent friction force $f_{r}$, and the friction torque $M$ at the contact interface. After the drill string exerts pressure into the wall, we suppose the contact makes a circular profile 
of radius $a$ on a side; the approaching distance is $\alpha$. The formulae of contact force and other parameters are deduced by Hertzian contact theory and logical-spring-damper theory [15]:

$$
\begin{gathered}
\alpha=\left[9 \pi^{2} N^{2}\left(\frac{1-\mu_{1}^{2}}{\pi E_{1}}+\frac{1-\mu_{2}^{2}}{\pi E_{2}}\right)^{2}\left(R_{1}-R_{2}\right)\right. \\
\left.\cdot\left(16 R_{1} R_{2}\right)^{-1}\right]^{1 / 3} \\
a=\left[3 \pi N\left(\frac{1-\mu_{1}^{2}}{\pi E_{1}}+\frac{1-\mu_{2}^{2}}{\pi E_{2}}\right) R_{1} R_{2}\right. \\
\left.\cdot\left(4\left(R_{1}-R_{2}\right)\right)^{-1}\right]^{1 / 3} .
\end{gathered}
$$

Set resistance coefficient between drill string and borehole wall $K$; for the situation with contact, the associated normal force is modeled as

$$
\begin{aligned}
& K \alpha+c v_{r}=N, \\
& N=\left(\frac { 1 } { 3 } K \left[9 \pi^{2}\left(\frac{1-\mu_{1}^{2}}{\pi E_{1}}+\frac{1-\mu_{2}^{2}}{\pi E_{2}}\right)\left(R_{1}-R_{2}\right)\right.\right. \\
& \left.\cdot\left(16 R_{1} R_{2}\right)^{-1}\right]^{1 / 3} \\
& \left.-\frac{1}{3}\left(\sqrt[3]{Y_{1}}+\sqrt[3]{Y_{2}}\right)\right)^{3} \\
& Y_{1}=-\left(9 \pi^{2} K^{3}\left(\frac{1-\mu_{1}^{2}}{\pi E_{1}}+\frac{1-\mu_{2}^{2}}{\pi E_{2}}\right)^{2}\left(R_{1}-R_{2}\right)\right. \\
& \left.\cdot\left(16 R_{1} R_{2}\right)^{-1}\right) \\
& +\frac{9}{2} \\
& \cdot\left(-3 c v_{r}\right. \\
& +\left(9 c^{2} v_{r}^{2}\right. \\
& +3 \pi^{2} K^{3}\left(\frac{1-\mu_{1}^{2}}{\pi E_{1}}+\frac{1-\mu_{2}^{2}}{\pi E_{2}}\right)^{2}\left(R_{1}-R_{2}\right) \\
& \left.\left.\cdot\left(4 R_{1} R_{2}\right)^{-1}\right)^{1 / 2}\right) \text {, }
\end{aligned}
$$

where $N$ is normal force, $R_{1}$ and $R_{2}$ are hole radius and the outer radius of the drill string at the contact interface, $\mu_{1}$ and $\mu_{2}$ are Poisson's ratio of the wall rock and Poisson's ratio of the drill string, $E_{1}$ and $E_{2}$ are the elastic modulus of the wall rock and the elastic modulus of the drill string, $K$ and $c$ are resistance coefficient between drill string and borehole wall and damping coefficient, $v_{r}$ is velocity component along the borehole radius direction before contact according to (7).

The normal contact force model presented here is different from the models of the studies [17-20], in which perfect models have been assumed. In the finite element numerical simulation of calculating the drag and torque, the rigid and flexible contact method is applied to deal with the contact relation between drill string and borehole; once it monitors the contact, the contact force according to (7) is joined with matrix $[P]$ of (3) to participate in the subsequent calculations.

2.4. Drag and Torque Model of Drill String Element. The forces imposed on pipe include the weight of the drill string in air; axial tension of landing by rig, torque, and friction force exists between drill stem and wall; buoyancy effect occurs when the drilling string is submerged in drilling fluid, viscous friction torque, and so on.

Taking the drill string element " $i$ " in three-dimensional space as the subject, its forces are analyzed and calculated. Subscript Arabic numbers "1" and "2" represent the bottom and top locations of the drill string element where the force applies. Figure 2 shows the force balance for the element. The governing equations of forces can be obtained as follows: 


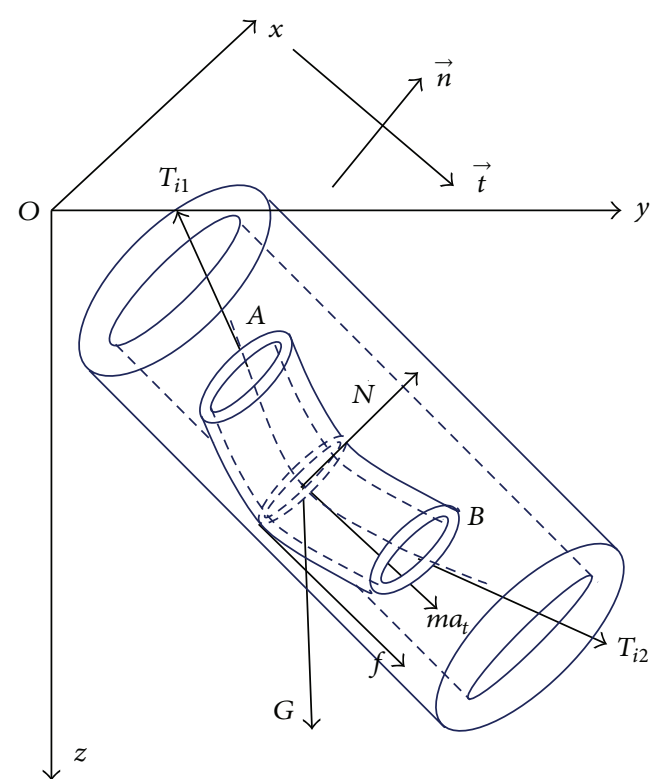

Figure 2: The forces acting on the drill string element.

$\vec{t}$ direction is

$$
\begin{aligned}
\bar{m}_{i} a_{i t}= & -T_{i 1} \cos \left(\frac{\vec{T}_{i 1}}{\left|\vec{T}_{i 1}\right|}, \vec{t}\right)+T_{i 2} \cos \left(\frac{\vec{T}_{i 2}}{\left|\vec{T}_{i 2}\right|}, \vec{t}\right) \\
& +\bar{m}_{i} g \cos (\vec{z}, \vec{t}) \\
& -\left[\operatorname{mgs}\left(f\left(\vec{v}_{i 1}\right)\right) f_{i 1}+\operatorname{mgs}\left(f\left(\vec{v}_{i 2}\right)\right) f_{i 2}\right] ;
\end{aligned}
$$

$\vec{n}$ direction is

$$
\begin{aligned}
\bar{m}_{i} a_{i n}= & T_{i 1} \sin \left(\frac{\vec{T}_{i 1}}{\left|\vec{T}_{i 1}\right|}, \vec{t}\right)+T_{i 2} \sin \left(\frac{\vec{T}_{i 2}}{\left|\vec{T}_{i 2}\right|}, \vec{t}\right) \\
& -\bar{m}_{i} g \sin (\vec{z}, \vec{t}) \\
& +\operatorname{mgs}\left(f\left(u_{i 1_{\tau}}\right)\right) f\left(u_{i 1_{\tau}}+r_{i 1}-R_{i 1}\right) N_{i 1} \\
& +\operatorname{mgs}\left(f\left(u_{i 2_{\tau}}\right)\right) f\left(u_{i 2_{\tau}}+r_{i 2}-R_{i 2}\right) N_{i 2},
\end{aligned}
$$

where $a_{i t}$ and $a_{i n}$ are the axial acceleration and normal acceleration of drill string; $\cos \left(\vec{T}_{i 1} /\left|\vec{T}_{i 1}\right|, \vec{t}\right)$ is the cosine value between vector $\vec{T}_{i 1} /\left|\vec{T}_{i 1}\right|$ and vector $\vec{t} ; T_{i 1}$ and $T_{i 2}$ are axial forces; $\cos (\vec{z}, \vec{t})$ is the cosine value between vector $\vec{z}$ and vector $\vec{t} ; \operatorname{mgs}(x)$ is the sign function; when the value of $x$ is negative, the return value is -1 ; if not, the return value is $1 ; f\left(\vec{v}_{i 1}\right)$ and $f\left(\vec{v}_{i 2}\right)$ are functions to judge the axial velocity direction of a node in real time; when the direction of $\vec{v}_{i 1}$ and $\vec{v}_{i 2}$ is identical to the positive direction of axial direction, the value of function is 1 ; if not, the value is $-1 ; f_{i 1}$ and $f_{i 2}$ are the axial frictional forces; its value is equal to the product of the sliding friction coefficient and contact force $f=\mu N ; \sin \left(\vec{T}_{i 1} /\left|\vec{T}_{i 1}\right|, \vec{t}\right)$ and $\sin \left(\vec{T}_{i 2} /\left|\vec{T}_{i 2}\right|, \vec{t}\right)$ are the sines of those angles; $u_{i 1_{\tau}}$ and $u_{i 2_{\tau}}$ are lateral displacements of the node; $f\left(u_{i 1_{\tau}}\right)$ and $f\left(u_{i 2_{\tau}}\right)$ are functions to judge the lateral displacement direction of a node in real time; when the drill string position relative to the wellbore is on the low side, the value of function is 1 ; when the drill string position relative to the wellbore is on the high side, the value is $-1 ; f\left(u_{i 2_{\tau}}+r_{i 2}-\right.$ $\left.R_{i 2}\right)$ and $f\left(u_{i 1_{\tau}}+r_{i 1}-R_{i 1}\right)$ are functions to judge whether the drill string and borehole wall contact in a calculation; when the values of annular tolerances between drill string and borehole wall $u_{i 1_{\tau}}+r_{i 1}-R_{i 1}$ and $u_{i 2_{\tau}}+r_{i 2}-R_{i 2}$ are zero or negative, the values of functions are 1 showing that drill string contacts with one side of the borehole wall; if not, the values of functions are 0 showing that drill string contacts no side of the borehole wall; $N_{i 1}$ and $N_{i 2}$ are contact forces; its values can be calculated based on equation.

When the element satisfies (9) and (10), the equation for friction torque can be written as

$$
T_{\tau}=f_{\tau} R
$$

where $f_{\tau}$ is the tangential frictional forces, its value is equal to the product of the tangential friction coefficient and contact force $f_{\tau}=u^{\prime} N$, and $u^{\prime}$ is the tangential friction coefficient.

Then, synthesizing friction torque and active torque, we can get the equation for torque of a node:

$$
T=T_{\tau}+T^{\prime}
$$

The above equations of drag and torque are the core content of full well system dynamics modeling. By using mechanics parameters such as velocity and acceleration of drill element node based on (3), results will be obtained by iterative calculation; after each iteration, the parameters will be amendment. When the boundary conditions of the top and end of the drill string are met, we can get the friction torque of the whole drill string.

As is apparent from the above model, what makes these equations different between most of the industry widely used torque and drag models based on the soft string model or often called a "cable" or "chain" is that it no longer assumes that the drill string is deformed to the shape of wellbore and has continuous surface contact area between the drill string and borehole but introduces stochastic boundary method for prediction of contact stress. The relations between the drill string and borehole can be contact states, as well as discrete state; at the same time considerations regarding the effects of drill pipe movement could also have been implemented in the present model. In the complex wellbore profiles with microand macrotortuosities, the soft string model may introduce errors and cause misinterpretation of drilling problems. Along with this, when the drill string position relative to the wellbore is on the high side, the soft string model cannot predict this situation which in some cases will lead to errors in torque and drag prediction; it excludes the influence on it, but, for this model, (10) is workable. So compared with the soft string model, this calculating method is more approaching practice, because it is based on the drilling string system dynamics. 


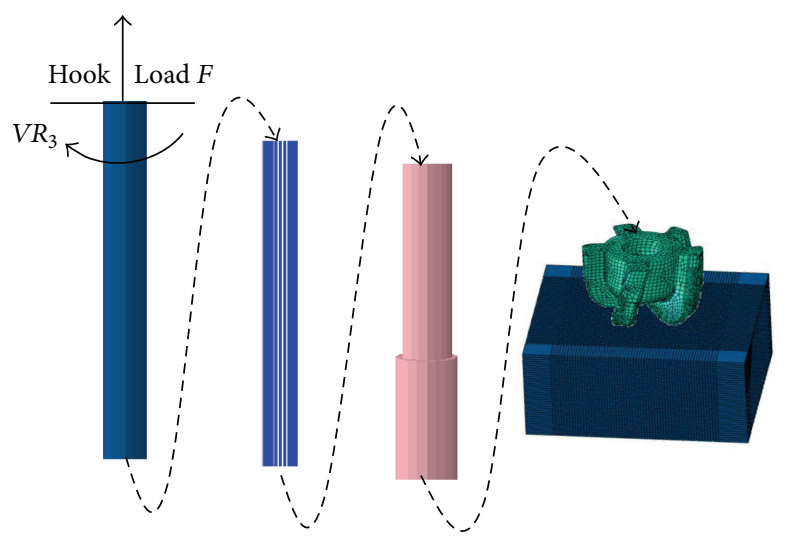

FIGURE 3: The drill string system numerical model.

\section{Dynamic Analysis of Drag and Torque in Highly Deviated Well}

Based on dynamic drag and torque model in highly deviated well, a dynamics model for describing rotary drill in drilling of highly deviated well from Jidong Oilfield in China was established; it considered the drill string-borehole-drill bitrock as the "drill string vibration system." In this paper, the system vibration of the drill string is simplified to a high dimensional multidegree of freedom system to analyze with appropriate load and boundary conditions those determined by the construction parameters. The nonlinear mass-springdamper mechanical system has been used to replace drill string in highly deviated well for analysis drag and torque considering drill string service environment and friction collision between drill string and borehole of drill string and the buoyancy of the mud, and so on. The three-dimensional finite-element model was developed using a finite element preprocessor module of ABAQUS; drill string, borehole, drill bit, and rock were modeled by spatial two nodes beam element BEAM31, rigid body shell element R3D4, rigid body shell element R3D4, and three-dimension solid element C3D8R, respectively, by the meshing techniques. The numerical model should look like that shown in Figure 3. Using numerical method, the results of drag and torque of the system can be obtained through work station's long time work.

3.1. Initial Data for Calculation. Calculation of one of Jidong Oilfield highly deviated wells is by applying this theoretical model and torque and drag analysis. The drilling structure of fourth drilling section is $\Phi 215.9 \mathrm{~mm}$ bit $\times 0.34 \mathrm{~m}+\Phi 172 \mathrm{~mm}$ screw $\times 7.69 \mathrm{~m}+\Phi 165$ check valve $\times 0.50 \mathrm{~m}+\mathrm{F} 206 \times 1.53 \mathrm{~m}$ $+\Phi 165$ Drill collar $\times 9.09 \mathrm{~m}+$ MWD $\times 2.17 \mathrm{~m}+\Phi 165$ Drill collar $\times 9.47 \mathrm{~m}+\Phi 139.7$ heavy weight drill pipe $\times 84.53 \mathrm{~m}(9$ drill pipes $)+\Phi 178$ drilling jar $\times 3.57 \mathrm{~m}+\Phi 139.7$ heavy weight drill pipe $\times 84.53 \mathrm{~m}(9$ drill pipes $)+139.7$ drill pipe + cock + Kelly.

In practical modeling, according to the measured borehole trajectory parameters established drill pipe and borehole, the well depth is $4305 \mathrm{~m}$, the actual well path is as shown

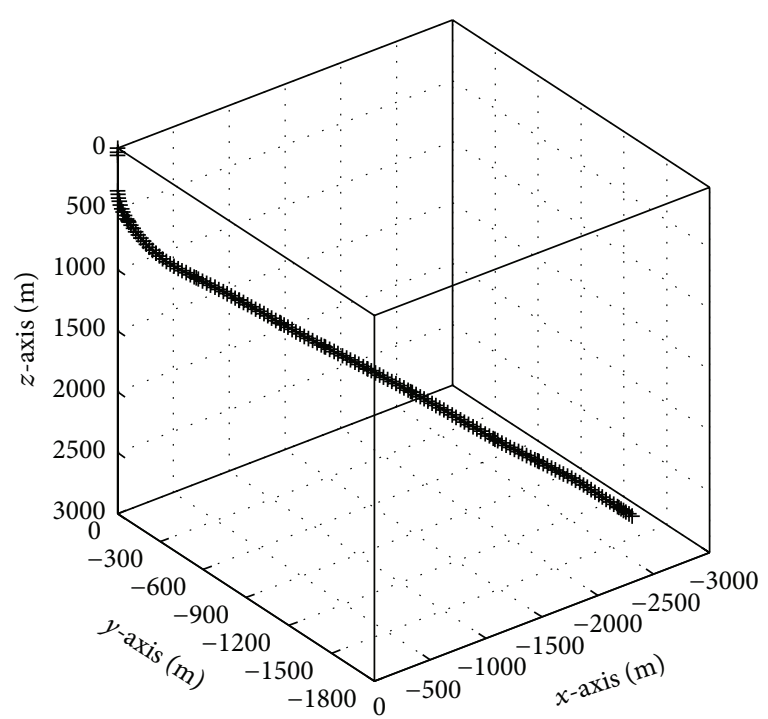

FIGURE 4: 3D actual wellbore path of NP13-X1042.

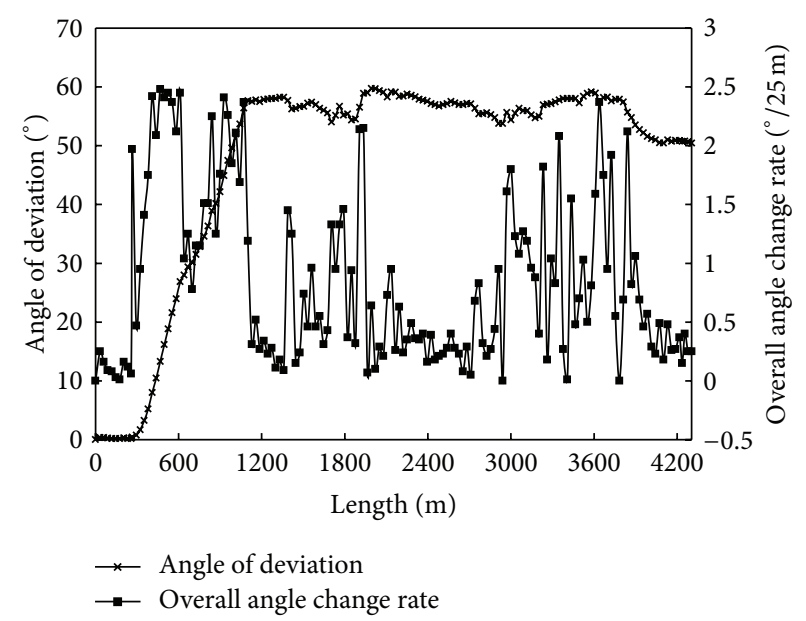

Figure 5: Angle of deviation and overall angle change rate.

in Figure 4, angle of deviation and overall angle change rate as shown in Figure 5, casing with inside diameter $\Phi 222.96$ mm running depth is $2986.53 \mathrm{~m}$, and the rest is open hole wall.

The damping behavior is considered as Rayleigh damping (a quadratic expression for the energy dissipation rate), which is proportional to the mass and stiffness of each mode. Time increments should be defined properly to achieve efficient computation and capture dynamics in the highest frequency range of interest. The stability limit dictates the maximum time increment used by ABAQUS Explicit. The stability limit will be defined based on the element length and the wave speed inside the material $\left(\Delta t_{\text {stable }}=L_{e} / C_{d}\right)$ [14]. Other parameters given in Table 1 are considered.

\subsection{Numerical Results and Discussions}

3.2.1. Contact Analysis between the Drill String and the Borehole Wall. Figure 6 shows distribution of contact force 
TABle 1: Parameters used in the simulations.

\begin{tabular}{lccc}
\hline$\mu_{1}=0.33$ & Poisson's ratio of the wall rock & WOB $=6$ & Weight on bit (ton) \\
$\mu_{2}=0.3$ & Poisson's ratio of the drill string & $\Omega=70$ & Angular velocity (rad/s) \\
$E_{1}=51.5 \times 10^{9}$ & Elastic modulus of the rock $\left(\mathrm{N} / \mathrm{m}^{2}\right)$ & $\rho=7860$ & Drill string density $\left(\mathrm{kg} / \mathrm{m}^{3}\right)$ \\
$E_{2}=210 \times 10^{9}$ & Elastic modulus of the drill string $\left(\mathrm{N} / \mathrm{m}^{2}\right)$ & $G=7.6923 \times 10^{10}$ & Shear modulus $\left(\mathrm{N} / \mathrm{m}^{2}\right)$ \\
$K=6.57 \times 10^{11}$ & Resistance coefficient $(\mathrm{N} / \mathrm{m})$ & $\mu=0.1-0.4$ & Sliding friction coefficient \\
$C=1.56 \times 10^{6}$ & Damping coefficient $(\mathrm{N} \cdot \mathrm{s} / \mathrm{m})$ & $\mu^{\prime}=0.1-0.4$ & Tangential friction coefficient \\
\hline
\end{tabular}

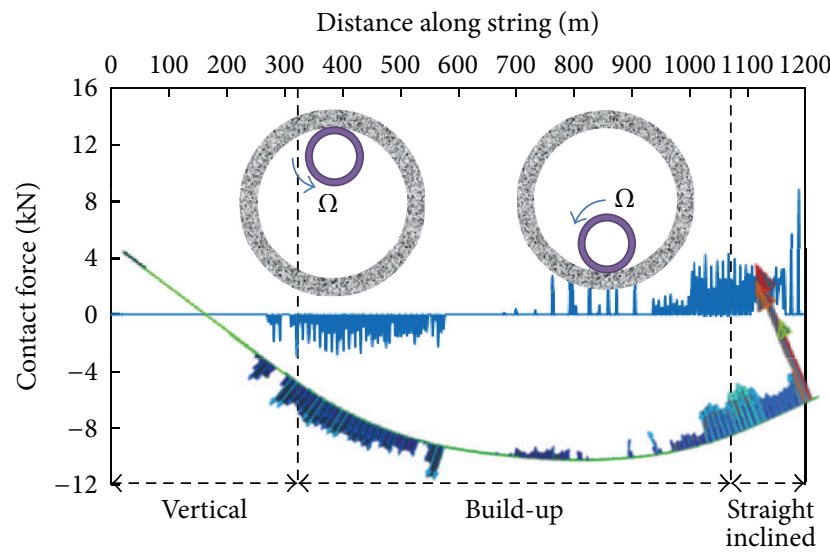

(a) $t=2.5 \mathrm{~s}$

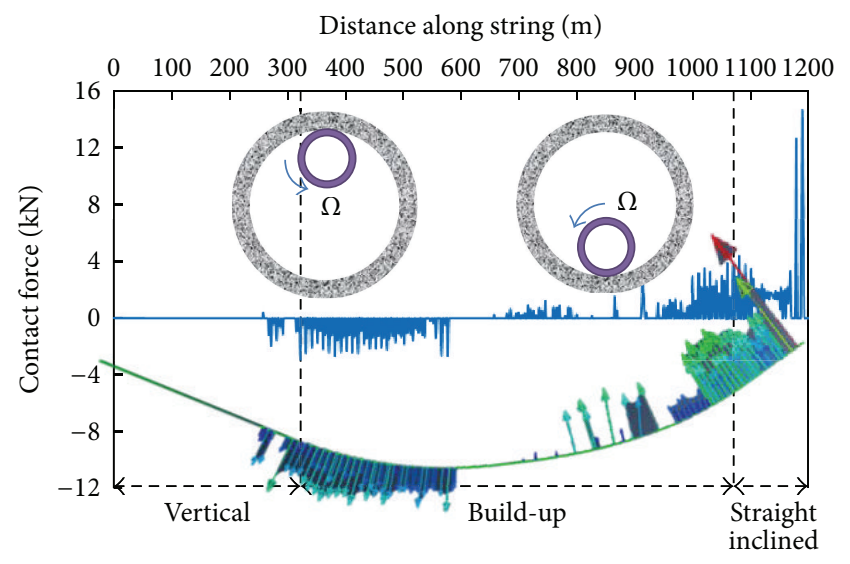

(b) $t=5.0 \mathrm{~s}$

Figure 6: Distribution of contact force on length for 0 1200 m drill string for highly deviated well at different times.

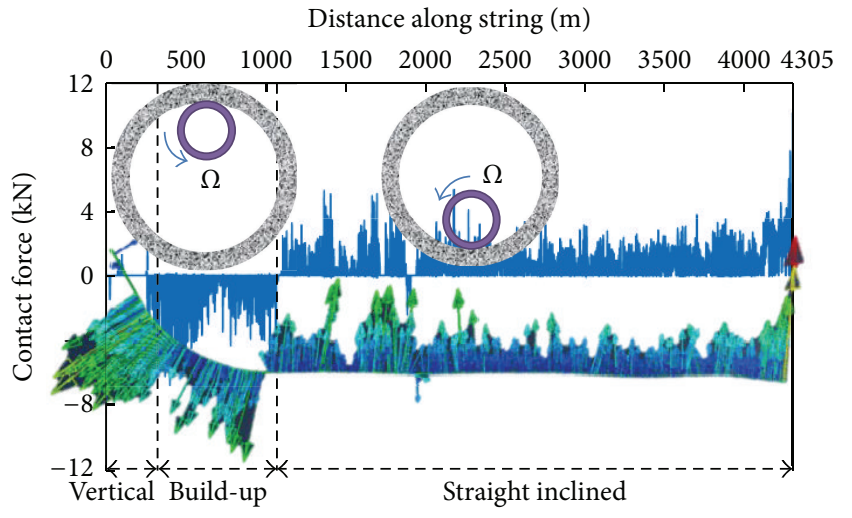

(a) $t=2.5 \mathrm{~s}$

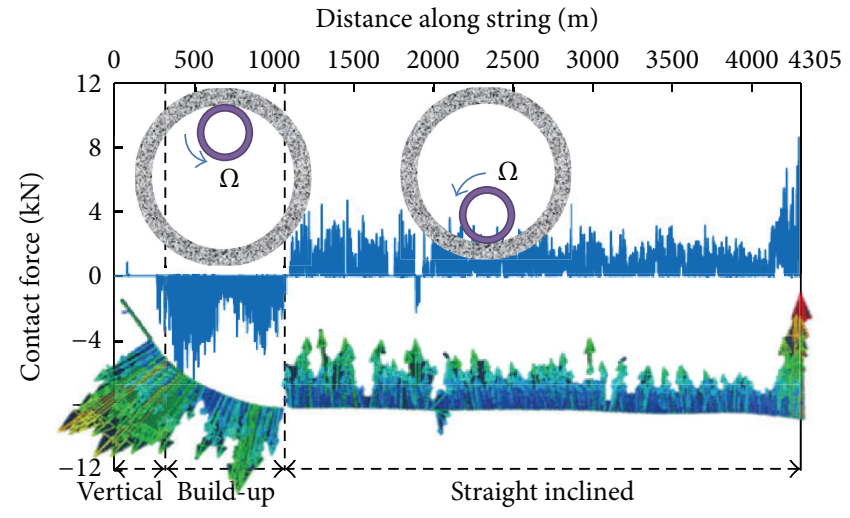

(b) $t=5.0 \mathrm{~s}$

FIgURE 7: Distribution of contact force on length for 0 4305 $\mathrm{m}$ drill string for highly deviated well at different times.

on length of $0 \sim 1200 \mathrm{~m}$ drill string for highly deviated well at different times, the average weight on bit is 6 ton, and friction factor is 0.3 . Figure 7 shows distribution of contact force on length of $0 \sim 4305 \mathrm{~m}$ drill string for highly deviated well at different times at the average weight on bit equal to $6 \mathrm{t}$; friction factor is 0.3 . From the figures, we can find that almost it has no node of drill string contacting borehole wall in the vertical section, but, for the contact part, the contact position and the value of the contact force go through instantaneous changes over time and there exist continuous contact and discontinuous contact areas. The value of the contact force produced varies between approximately 0 and $14 \mathrm{kN}$. In general, the contact force of drill string in build-up section and the part exposed to an axial compression is bigger than other parts. The contact state between drill string and borehole wall can be divided into two main parts; the contact force is negative in front part of drill string; the contact force is positive in subsequent sections of drill string and there exists a cut-off point to divide positive numbers from negative ones.

When the contact force is positive, it is pointing downward and this case illustrates that these drill string nodes contact the wellbore at the high side due to the pull forces; if 


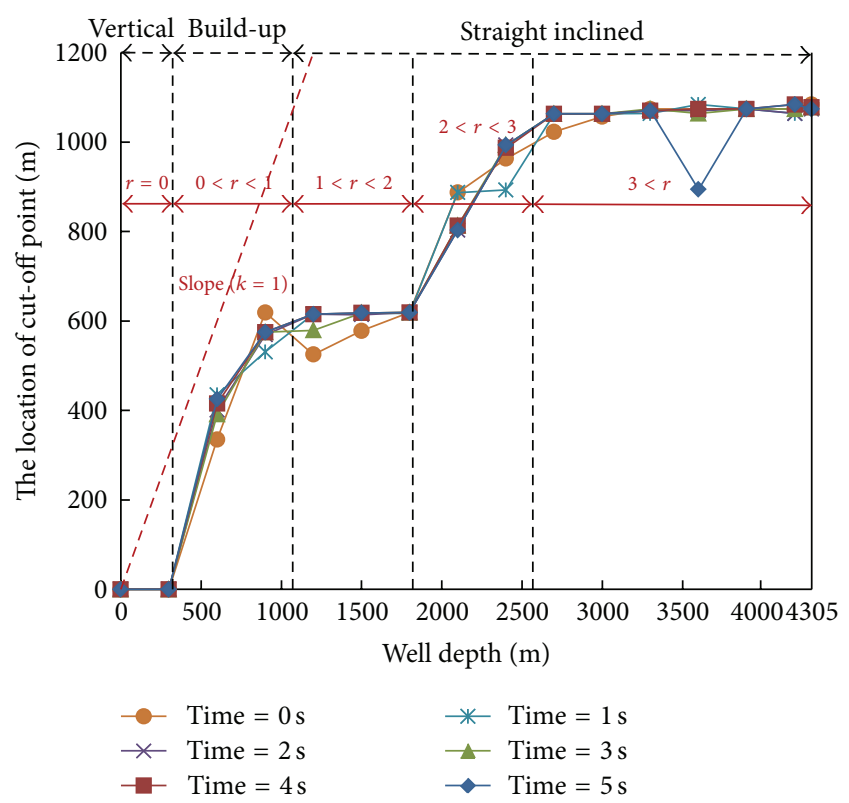

FIGURE 8: Distribution of cut-off point for well depth at different times.

the direction of the contact force acting on the node is going upwards, this means the contact force is negative and these nodes contact the wellbore at the low side under the influence of gravity. When the bit depth is $1200 \mathrm{~m}$, the cut-off point is found roughly halfway in the build-up section, but, for $4305 \mathrm{~m}$, the location of cut-off point is not the same,; instead, it is found in tail of build-up section. The contact between drill string and borehole wall is only expected to grow as the well depth.

Dynamic drag and torque model in highly deviated well can be visual display of the contact state between drill string and borehole wall and numerical results of the contact force and friction force. The frequent impact may result in the drill string wear and leakage, so the distribution of contact force on length for drill string can predict the wear location of the drill string and guide tools installation which can reduce friction force and friction torque.

It can be known from the analysis of the contact between drill string and borehole wall, in most cases, that drill string contacts the wellbore at the low side under the influence of gravity in angle maintaining interval. However, the situation is not simpler in build-up section; drill string can contact the wellbore at either low side or high side for the pulling effect of drill string in both vertical section and angle maintaining interval. Figure 8 shows distribution of cut-off point for well depth. In terms of the overall shape of distribution, the curve is roughly three ladder-like distributions along with the oil well depth increasing. There is no cut-off point caused by noncontact between 0 and $300 \mathrm{~m}$; for depth $300 \mathrm{~m}-900 \mathrm{~m}$, the rule of formation of cut-off point location values has parabolic increase trend with the increasing depth. When well depth reaches $1200 \mathrm{~m}-1800 \mathrm{~m}$, cut-off point location is virtually unchanged around $610 \mathrm{~m}$, which is roughly halfway in the build-up section; that is, these nodes above the middle location of build-up section will be contacted with borehole wall at high side and the behind nodes will contact the low side during drilling with drilling operation in this interval. Parabolic increase trend with the increasing depth also occurs with depth $1800 \mathrm{~m}-2700 \mathrm{~m}$, cut-off point location varies from about $619 \mathrm{~m}$ in well depth $1800 \mathrm{~m}$ to about $1063 \mathrm{~m}$ in well depth $2700 \mathrm{~m}$. Differently, the cut-off point location is virtually unchanged around $1075 \mathrm{~m}$ between well depths $2700 \mathrm{~m}$ and $4305 \mathrm{~m}$; this suggests that once the nodes of drill string in build-up section contact wall, location of the contact must be the high side of borehole with drilling operation in this interval.

By computations and analysis, it is found that distribution of cut-off point associates with the ratio between the length of the nonvertical section and the total length of build-up section of hole. Suppose the ratio equals $r$; we can use $0<$ $r<1$ corresponding to the first parabola curve, $1<r<2$ corresponds to the second platform stage, $2<r<3$ corresponds to the second parabola curve, and $3<r$ corresponds to the third platform stage. The point to cut off contact position between low side and high side is an important feature to distinguish between the dynamic method and differential characteristic method or other numerical methods. Differential form analytical solution has fewer hypothesis of contact high side which may bring about great errors. But for other numerical solution methods which can judge the contact side, more or less there is little error in the calculation for getting the cut-off point position and moreover its position will not change with well depth; this is simply irresponsible.

Calculation of cut-off point position will help to determine the damage or failure position of casing in drilling operation. Wear position of casing generally occurs in the high side of casing.

Figure 9(a) shows transient processes of contact force in the node located $600 \mathrm{~m}$ for $4305 \mathrm{~m}$ drill string at the average weight on bit of 6 tons and friction factor 0.3; Figure 9(b) shows transient processes of contact force in the node located $3000 \mathrm{~m}$. The node located $600 \mathrm{~m}$ belongs to drill string in build-up section; from its transient processes of contact force, we can see that it dashes upon borehole wall frequently and its contact state can be divided into the gap contact and continuous contact; for example, the contact state is gap contact in $0.5 \mathrm{~s}-1 \mathrm{~s}$ period; however, the contact state turns into continuous contact. The node located $3000 \mathrm{~m}$ belongs to drill string in angle maintaining interval; its contact state probably is just the same as the node located $600 \mathrm{~m}$ which also includes gap contact and continuous contact. The value of contact force in the node located $600 \mathrm{~m}$ produces varies between approximately 0 and $6 \mathrm{kN}$; for the node located $3000 \mathrm{~m}$, however, the value produces varies between approximately 0 and $3 \mathrm{kN}$; by contrast, it has become much smaller.

3.2.2. Drag Analysis. Figure 10 shows calculated hook load (not including hook and top drive weight) for well depth at different friction factor; the average weight on bit is 6 tons; rotate speed is $70 \mathrm{rad} / \mathrm{s}$. With drilling vertical section (0$322.9 \mathrm{~m})$ and build-up section $(322.9 \mathrm{~m}-900 \mathrm{~m})$ in second section, hook load is hardly affected by the increase of friction 


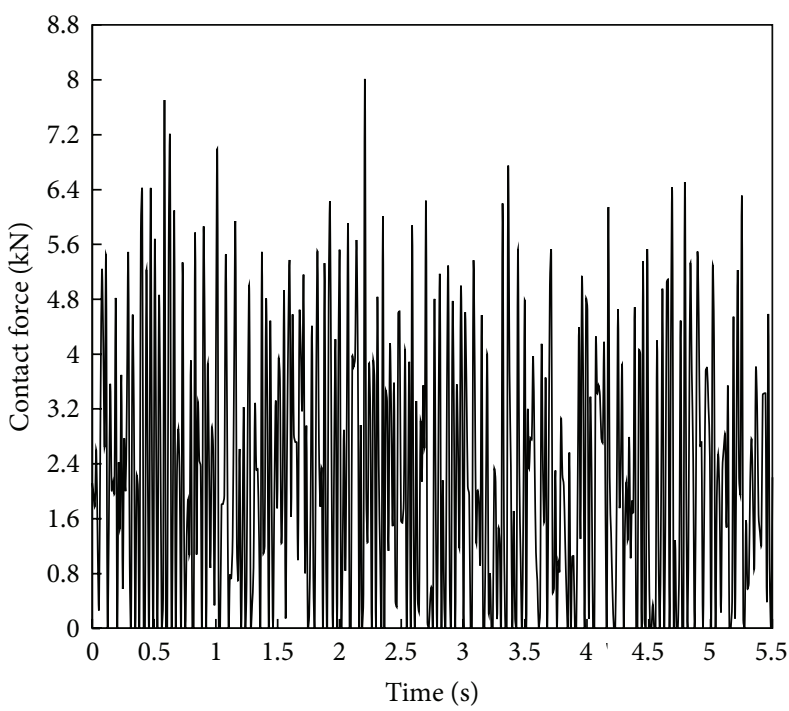

(a)

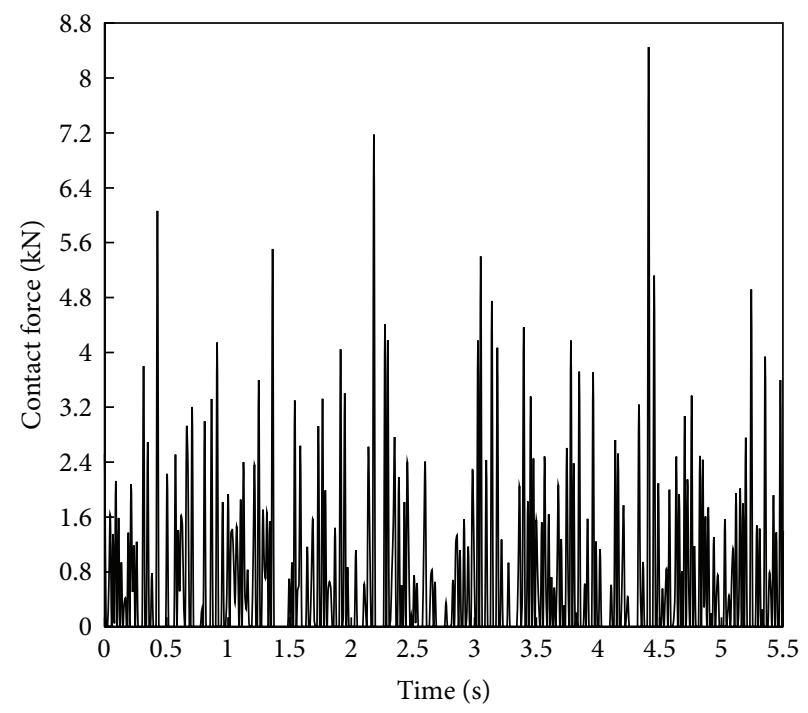

(b)

FIGURE 9: Contact force: (a) transient processes of contact force in the node located at $600 \mathrm{~m}$ for $4305 \mathrm{~m}$ drill string and (b) transient processes of contact force in the node located at $3000 \mathrm{~m}$ for $4305 \mathrm{~m}$ drill string.

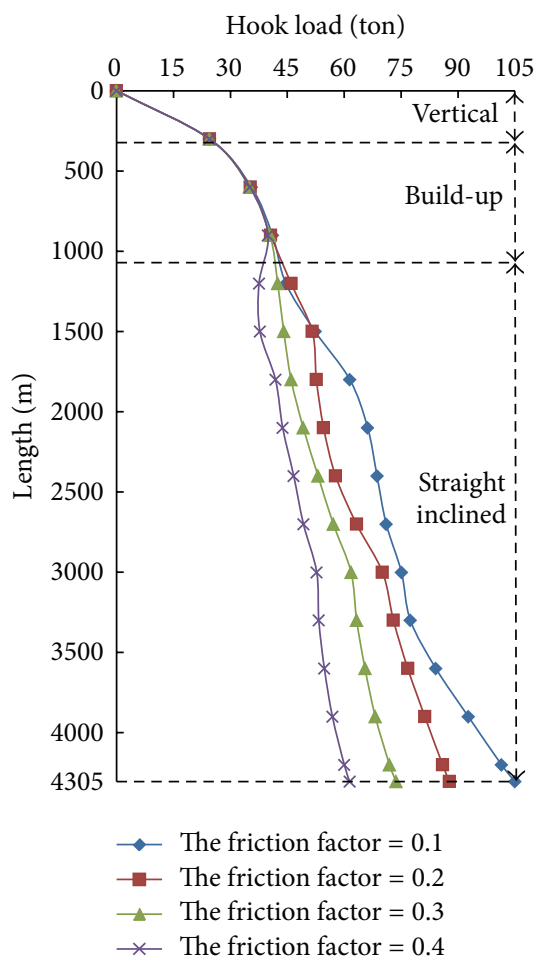

Figure 10: Calculated hook loads for well depth at different friction factors.

coefficient, although under the contact between drill string and borehole wall in build-up section. Hook load has great changes as the change of the larger friction factor (0.3-0.4) after well depth $900 \mathrm{~m}$; for smaller friction factor $(0.1-0.2)$, depth $1500 \mathrm{~m}$ is a cut-off point; before the depth $1500 \mathrm{~m}$ the change of hook load is not obvious; after $1500 \mathrm{~m}$ hook load begins to change significantly. Across the board, the widening of the value of hook load gap appears as the well depth increases at different friction factor, smaller friction factor results in greater increase of hook load; for larger friction factor, the increase of the hook becomes smaller. Change of sections and drilling tools $(300 \mathrm{~m}-1200 \mathrm{~m}$ is $\Phi 444.5 \mathrm{~mm}$ drill bit and corresponding drilling tools, $1500 \mathrm{~m}-3000 \mathrm{~m}$ is $\Phi 311.1 \mathrm{~mm}$ drill bit and corresponding tools, $3300 \mathrm{~m}-4305 \mathrm{~m}$ is $\Phi 215.9 \mathrm{~mm}$ drill bit and corresponding tools) will affect hook load: hook load presents different trends in different section, such as the hook load dates form a different change trend in $300 \mathrm{~m}$ to $1200 \mathrm{~m}$ against the change trends of $1500 \mathrm{~m}$ $3000 \mathrm{~m}$, and the change in trend of hook load just occurs when we vary the drilling tools to drill another section; for instance, there is a big difference between $3000 \mathrm{~m}$ of the third section and $3300 \mathrm{~m}$ of the fourth section; they each form their own change trend with other well depths in their own section at friction factor equal to 0.3. In the same section, the change trends of the hook load are also different with the change of the friction factors, in drilling well depth between $3300 \mathrm{~m}$ and $4305 \mathrm{~m}$; smaller friction factors (0.1-0.2) increase straightly the hook load, but larger friction factors (0.3-0.4) increase hook load into a parabola form. Calculated hook loads for well depth at different friction factors can be used for inversion of comprehensive friction factor between the drill string and borehole wall in real drilling; a good basis will be provided to choose friction factor during predicting hook load and friction torque for wells in adjacent area.

Figure 11(a) shows calculated axial friction force for well depth at different friction factors. After drilling vertical well section, axial friction force basic increases with the increase of friction factor; when the friction factor is 0.1-0.2, the axial friction force begins to change as the coefficient of friction in $1500 \mathrm{~m}$, but, for friction factor 0.3-0.4, axial friction force begins to change in $300 \mathrm{~m}$ of build-up section. Axial friction 


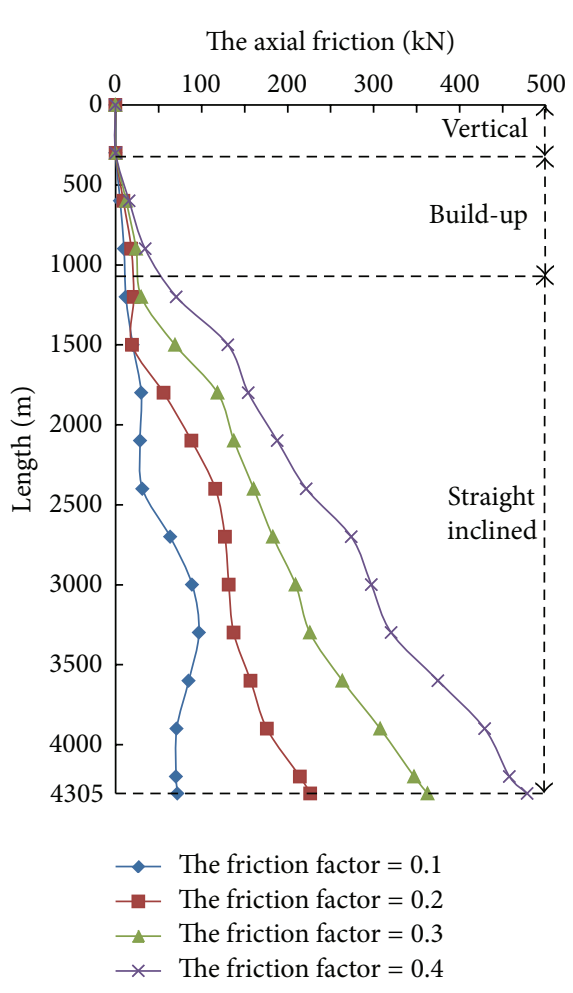

(a)

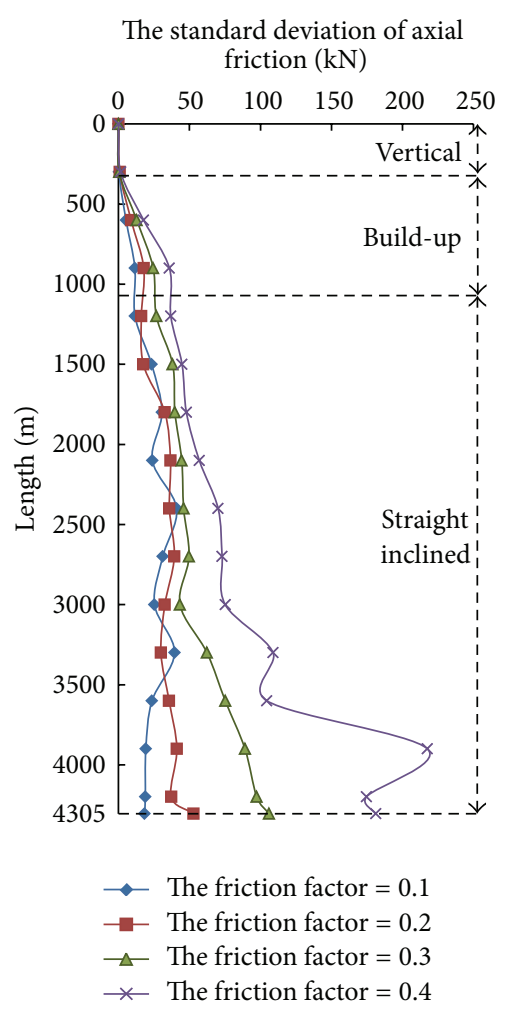

(b)

FIGURE 11: Friction force: (a) calculated axial friction force for well depth at different friction factors and (b) calculated standard deviation of axial friction force for well depth at different friction factors.

force has the same trend and change tendency as the hook load in each section. At the well depth $4305 \mathrm{~m}$, axial friction force is about $72 \mathrm{kN}$ at the friction factor 0.1 ; however, when the friction factor changes to 0.3 , the axial friction force is about $362.7 \mathrm{kN}$ of 5 times to friction factor 0.1 . Before drilling build-up section, the value of axial friction force far less than the hook load value is the reason that hook load is hardly affected by the increase of friction factor.

Figure 11(b) shows calculated standard deviation of axial friction force for well depth at different friction factors. When the friction factor is 0.1-0.2, the values of standard deviation of axial friction force cross each other and there is no significant difference before $3600 \mathrm{~m}$, the standard deviation of axial friction force starts increasing with increase of friction factor after $3600 \mathrm{~m}$. When the friction factor is 0.3-0.4, the standard deviation of axial friction force starts increasing with increase of friction factor after $600 \mathrm{~m}$. At the well depth $4305 \mathrm{~m}$, the standard deviation of axial friction force is about $18.5 \mathrm{kN}$ at the friction factor 0.1; the axial friction force is about 3.9 times of it; when the friction factor changes to 0.3 , the standard deviation of axial friction force is about $106 \mathrm{kN}$; at this time, the axial friction force is about 3.4 times of the standard deviation of axial friction force, but the standard deviation of axial friction has a larger time which can reach 5.7 to the friction factor 0.1 .
3.2.3. Torque Analysis. Figure 12(a) shows calculated friction torque for well depth at different friction factors. On the whole, the friction torque shows a trend of increase with the increase of the friction factor and the difference value of friction torque increases with the increase of well depth between two arbitrary friction factors in the same depth, but, for one arbitrary friction factor, friction torque almost linearly increases with depth and added value of friction torque is reducing in the process of friction factor changes from small to big in the same depth. The increasing slope of friction torque turns smaller with the friction factor increasing. Unlike the hook load change trend, in the process of completely drilling build-up section to whole wells, the friction torque changes with the increase of the friction factor and there is no cut-off point to change trend of the curve. When the friction factor changes between 0.1 and 0.4 , for the friction factor is 0.1 , the average of friction torque of whole well $4305 \mathrm{~m}$ is $13.61 \mathrm{kN} \cdot \mathrm{m}$, and when the friction factor is 0.3 , the average of friction torque is $34.6 \mathrm{kN} \cdot \mathrm{m}$, about 2.5 times of friction factor 0.1 , so the relationship of the friction torque between different friction factors is not cardinal number simply multiplied by the times of the friction factor increasing ratio.

Figure 12(b) shows calculated standard deviation of friction torque for well depth at different friction factors. 


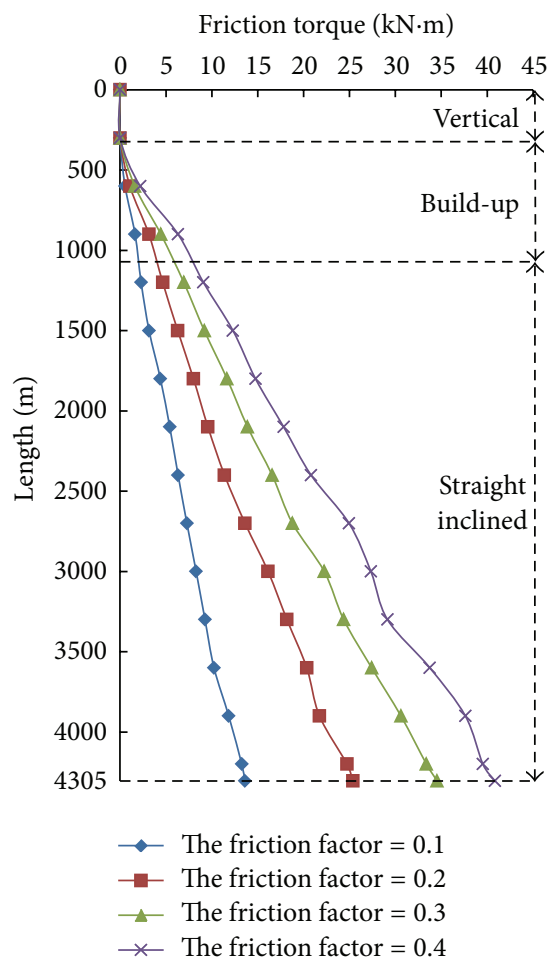

(a)

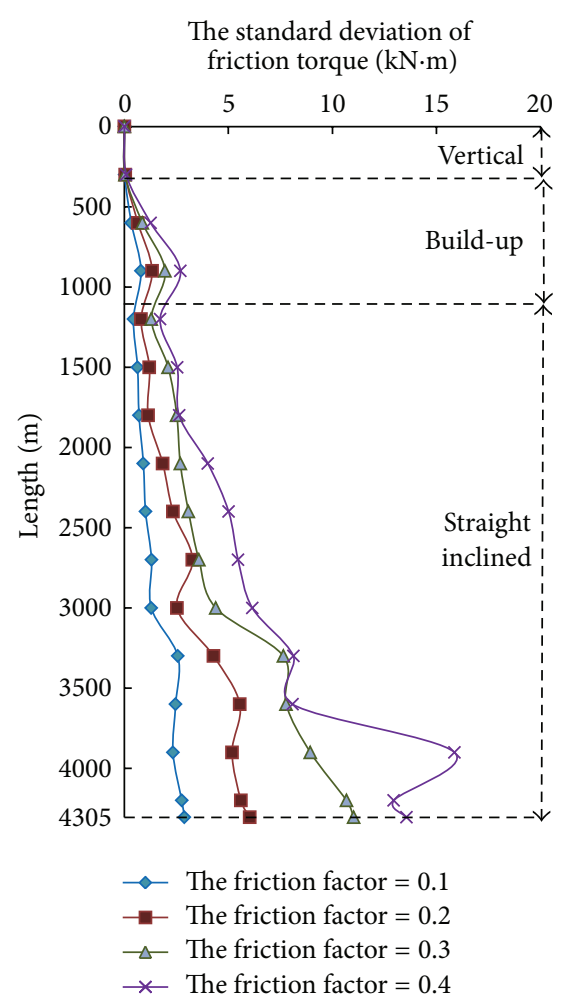

(b)

FIGURE 12: Friction torque: (a) calculated friction torque for well depth at different friction factors and (b) calculated standard deviation of friction torque for well depth at different friction factors.

The friction torque increases with the well depth increasing, so does the standard deviation of friction torque, and there shows phase step in standard deviation of friction torque change trend at different drill sections. As the same position of hole, difference values also increase with the increase of well depth, but being very different for a single curve between its overall trend and overall trend of friction torque for well depth is no longer a linear change. When drilling $900 \mathrm{~m}$ of build-up section, the standard deviation has a very volatile trade explaining that frequent contact and separation alternate appear between the drill string and borehole wall; here we should pay attention during drilling. When the friction factor changes between 0.1 and 0.4 , for the friction factor is 0.1 , the standard deviation of friction torque of whole well $4305 \mathrm{~m}$ is $2.9 \mathrm{kN} \cdot \mathrm{m}$; the friction torque is about 4.7 times of it, and when the factor is 0.3 , the standard deviation of friction torque is $11 \mathrm{kN} \cdot \mathrm{m}$; at this time, the friction torque is about 3.5 times of the standard deviation of friction torque, but the standard deviation has larger 3.8 times of the friction factor 0.1. The standard deviation of friction torque for well depth cannot be obtained by finite difference numerical solution, finite difference numerical solution assumes that the drill string has continuous surface contact area and the form of full contact with the wall; the bottom boundary of the drilling pressure numerical value is constant, so there is no torque standard deviation when calculating the friction torque. Relative to dynamics method, it sets the contact between drill string and borehole wall as random boundary that will more accord with actual situation.

Figure 13 shows calculated maximum static of friction torque for well depth at different friction factors. The change tendency is similar to the trend of average friction torque. When the friction factor is $0.1 \mathrm{in} 4305 \mathrm{~m}$ depth, the maximum static of friction torque is $16.5 \mathrm{kN} \cdot \mathrm{m}$; when the friction factor is 0.3 , the maximum static of friction torque is $45.6 \mathrm{kN} \cdot \mathrm{m}$ of 2.8 times of friction factor 0.1. When the maximum static of friction torque is close to the rated torque of drilling equipment, the temperature will rise for a long time drilling operation; when the problem gets more serious, it may damage the drilling string and the equipment, so the calculated maximum static of friction torque is vital for drilling safety in drilling process.

Throughout the drag and torque analysis, the friction torque and axial friction force both increase with the increase of the well depth, but, for the axial friction force in highly deviated well, no matter how much the axial frictional force is, the value will not get bigger than the total weight of the drill string; that is to say, there will always be a part of drill string weight to provide the downward force needed for the bits to efficiently break rock. Instead, maximum static of friction torque will be more than the rated torque of drilling equipment as the increasing of the well depth, so the maximum static of friction torque is the key factor to determine extension ability in highly deviated well. 


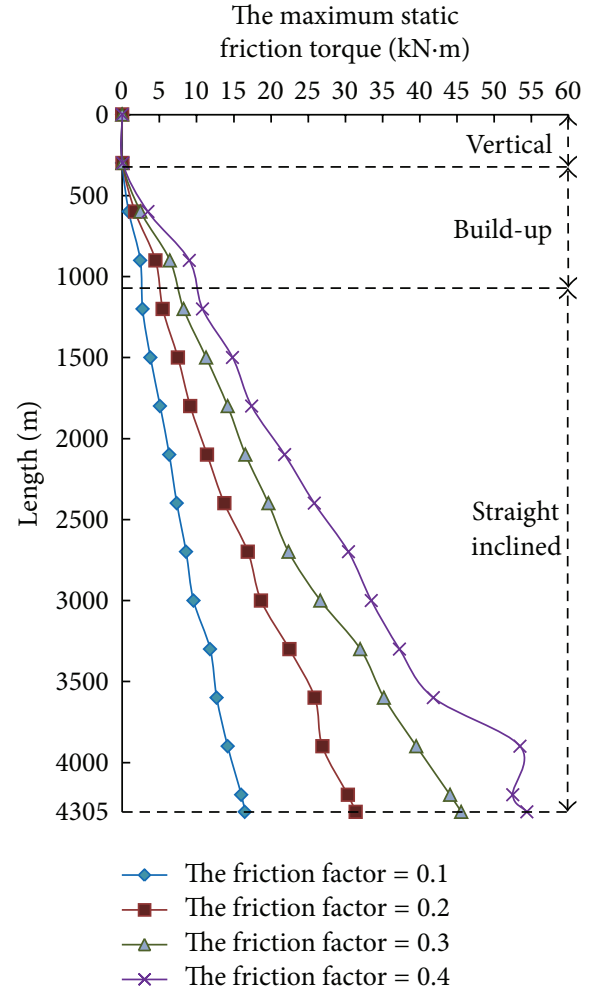

FIgURE 13: Calculated maximum static of friction torque for well depth at different friction factors.

\section{Conclusions}

Based on nonlinear coupling vibration of drilling string, three-dimensional nonlinear dynamic model and dynamic friction torque model were established in highly deviated well with mud drilling by using the finite element method to study the vibration rule of dynamic drag and friction torque of the drill string in rotary drilling.

(1) Dynamic drag and torque model established in this paper has a good adaptability under a complex threedimensional borehole trajectory in highly deviated well for real drilling; it has much less assumptions and its result is highly coincident with the actual drilling operations.

(2) In the process of calculating, continuous distribution of contact no longer has been used for assuming the contact relation of drill string and wellbore; stochastic boundary method was introduced for the prediction of contact stress. This mode can give threedimensional distribution of the contact for drill string and drill string node. It shows that the drill string of build-up section and those under axial compression are the part of whole well in most fierce collision and the nodes contact state are mainly divided into clearance contact and continuous contact. With the calculation, a cut-off point is found in drill string; it divides the contact state into high side borehole contact and low side borehole contact, and distribution of the cut-off point position is roughly three ladderlike curves along with the oil well depth increasing associated with the ratio between the length of the nonvertical section and the total length of build-up section of hole; when the ratio equals 1-2, the cutoff point position is basically near the halfway point of build-up section; when the ratio is more than 3 , the drill string is completely affixed to the high side of borehole in build-up section. Compared to the analytic solution using differential form, this method is available for solving the drill string contact which side of borehole, and this model can be employed for dynamics study; more importantly it makes the results more accessible and acceptable.

(3) Dynamic drag and torque model can predict hook load in different drilling sections and the change trend of the hook load along the well depth. When the axial friction force of drill string is less than $2 t$, the hook load is not affected by the influence of friction factor; when the axial friction force is greater than 2 tons, different rules are shown in calculated hook load along with the change of drilling sections and the change of the friction factor, and the change of the drill assembly will bring hook load a step change trend. The axial friction force and its average wave amplitude increase with increase of friction factor and well depth.

(4) Dynamic drag and torque model has the superiority compared with other analytical methods during the analysis of torque, which can get the friction torque, the standard deviation of friction torque, and the maximum static friction torque. Friction torque and maximum static friction torque basically have a linearly increased trend along with well depth, and added value of friction torque is reducing in the process of friction factor changes from small to big in the same well depth. Drilling section and the drill assembly have great influence on the standard deviation of friction torque. Compared with the axial friction, maximum static friction torque is mainly limitation for extending into ability of highly deviated well.

\section{Conflict of Interests}

The authors declare that there is no conflict of interests regarding the publication of this paper.

\section{Acknowledgments}

This work reported in this paper was supported by the National Oil \& Gas Key Project (2011ZX05050), Natural Science Foundation of China (51222406), New Century Excellent Talents in University of China (NCET-12-1061), Scientific Research Innovation Team Project of Sichuan colleges and universities (12TD007), and the Sichuan Youth Sci-tech Innovation Research Team of Drilling Acceleration (2014TD0025). 


\section{References}

[1] J. B. Noble, "Directional drilling apparatus and method," U.S. Patent, no. 5, 1992.

[2] C. A. Johancsik, D. B. Friesen, and R. Dawson, "Torque and drag in directional wells-prediction and measurement," Journal of Petroleum Technology, vol. 36, no. 7, pp. 987-992, 1984.

[3] X. He and A. Kyllingstad, "Helical buckling and lock-up conditions for coiled tubing in curved wells," SPE Drilling and Completion, vol. 10, no. 1, pp. 10-15, 1995.

[4] E. E. Maidla and A. K. Wojtanowicz, "Field method of assessing borehole friction for directional well casing," Middle East Oil Show SPE-15696-MS, 1987.

[5] J. H. Schamp, B. L. Estes, and S. R. Keller, "Torque reduction techniques in ERD Wells," in Proceedings of the IADC/SPE Drilling Conference, Society of Petroleum Engineers, Miami, Fla, USA, February 2006.

[6] C. J. Mason and C. K. D. Chen, "Step changes needed to modernize T\&D software," in Proceedings of the SPE/IADC Drilling Conference and Exhibition, pp. 20-22, Amsterdam, The Netherlands, February 2007.

[7] Z. Y. Han, "Study on 3D and 2d models of drill string torque and drag in hole," Journal of the China University of Petroleum, vol. 17, no. A00, pp. 44-49, 1993.

[8] D. L. Gao, "Some basic problems of elastic drillstring mechanics," Jouranl of China University of Petroleum, vol. 19, no. 1, pp. 24-35, 1995.

[9] Z. W. Song, D. L. Gao, and J. Ma, "New model for forecasting drag and torque in extended reach well," Oil Drilling \& Production Technology, vol. 6, 2006.

[10] J. Shuai, Y. M. Lv, and Q. K. Cai, "Finite element model of the drill string in a whole string in a whole well bore and its application," Acta Petrolei Sinica, vol. 1, 1995.

[11] X. H. Zhu, H. Tong, Q. Y. Liu, and L. X. Feng, "New method on calculation of torque and drag based on drilling string system dynamics," Journal of System Simulation, vol. 19, no. 21, pp. 4853-4856, 2007.

[12] X. H. Zhu, H. J. Zhu, and N. T. Si, "Effect calculation and analysis of rod drag and torque reducing tool," Journal of Marine Oil, vol. 28, no. 2, pp. 112-115, 2009.

[13] X. H. Zhu, H. Tong, and Q. Y. Liu, "Research on dynamic boundary condition between revolving drill string and borehole wall," Chinese Mechanical Engineering, vol. 18, no. 15, pp. 18331837, 2007.

[14] A. Ghasemloonia, D. G. Rideout, and S. D. Butt, "Vibration analysis of a drillstring in vibration-assisted rotary drilling: finite element modeling with analytical validation," Journal of Energy Resources Technology, Transactions of the ASME, vol. 135, no. 3, Article ID 032902, 2013.

[15] Y. A. Khulief, F. A. Al-Sulaiman, and S. Bashmal, "Vibration analysis of drillstrings with self-excited stick-slip oscillations," Journal of Sound and Vibration, vol. 299, no. 3, pp. 540-558, 2007.

[16] M. W. Dykstra, Nonlinear drill string dynamics [Doctoral dissertation], University of Tulsa, 1996.

[17] R. I. Leine, D. H. Van Campen, and W. J. G. Keultjes, "Stick-slip Whirl interaction in drillstring dynamics," Journal of Vibration and Acoustics, Transactions of the ASME, vol. 124, no. 2, pp. 209220, 2002.

[18] V. S. Tikhonov, A. I. Safronov, and M. Y. Gelfgat, "Method of dynamic analysis for rod-in-hole buckling," in Proceedings of the
ASME 8th Biennial Conference on Engineering Systems Design and Analysis, pp. 25-32, American Society of Mechanical Engineers, January 2006.

[19] C. M. Liao, B. Balachandran, and M. Karkoub, "Drill-string dynamics: reduced-order models," in Proceedings of the ASME International Mechanical Engineering Congress and Exposition, pp. 451-460, American Society of Mechanical Engineers, January 2009.

[20] X. Liu, N. Vlajic, X. Long, G. Meng, and B. Balachandran, "Nonlinear motions of a flexible rotor with a drill bit: stick-slip and delay effects," Nonlinear Dynamics, vol. 72, no. 1-2, pp. 61-77, 2013. 


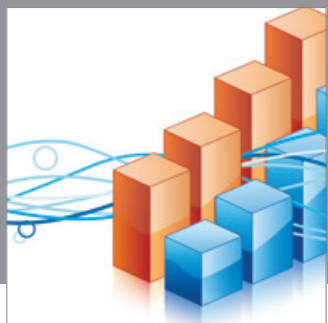

Advances in

Operations Research

mansans

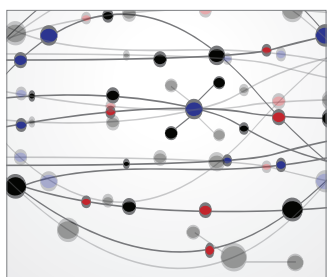

The Scientific World Journal
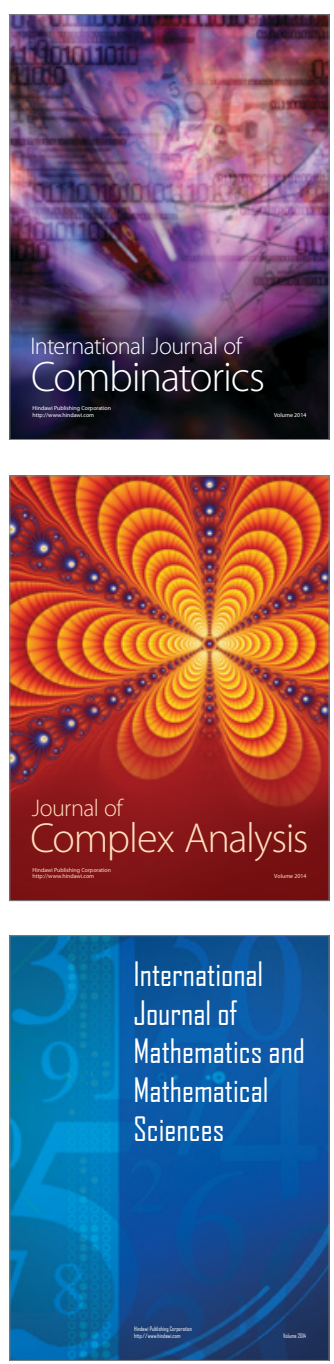
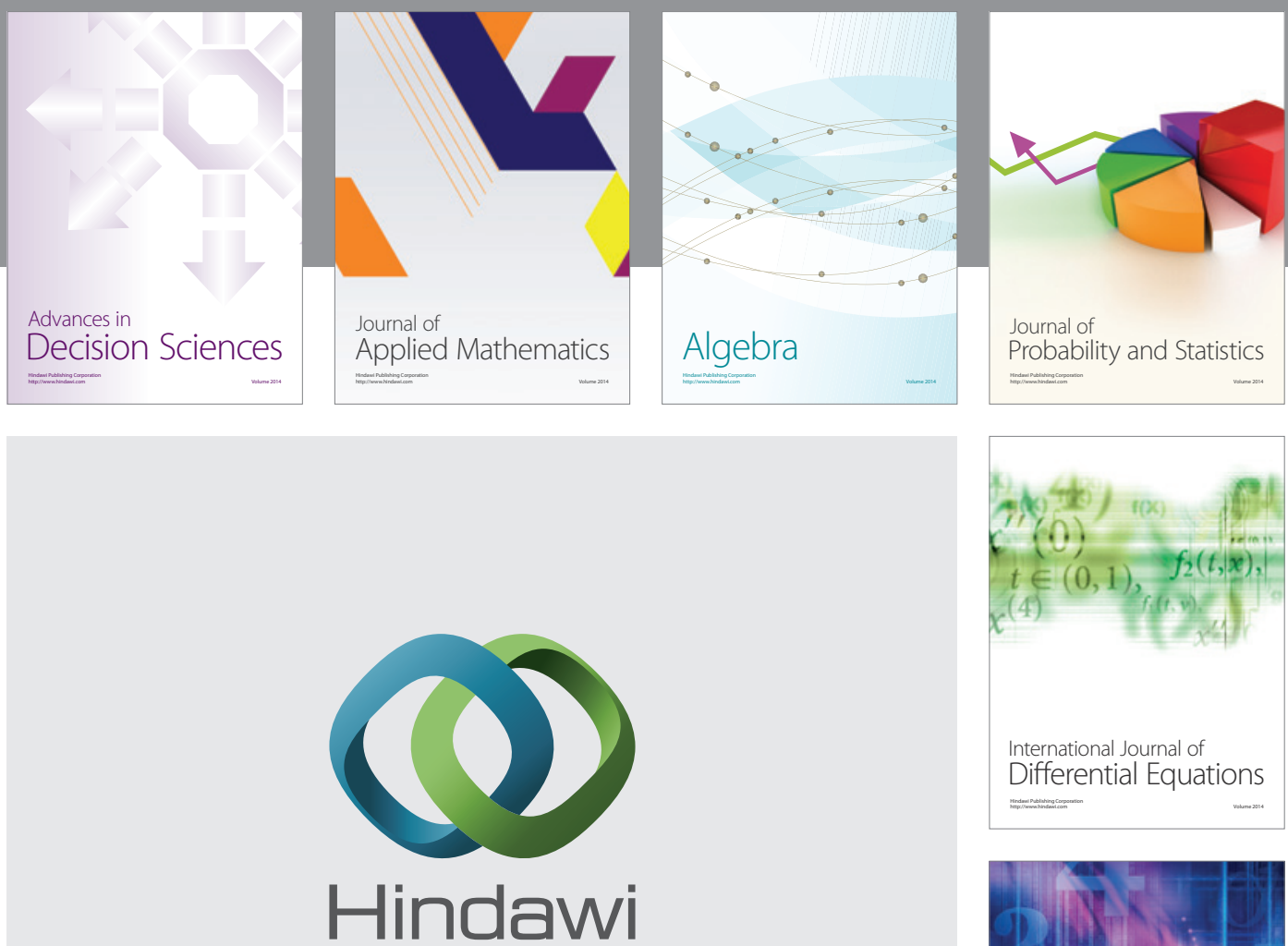

Submit your manuscripts at http://www.hindawi.com
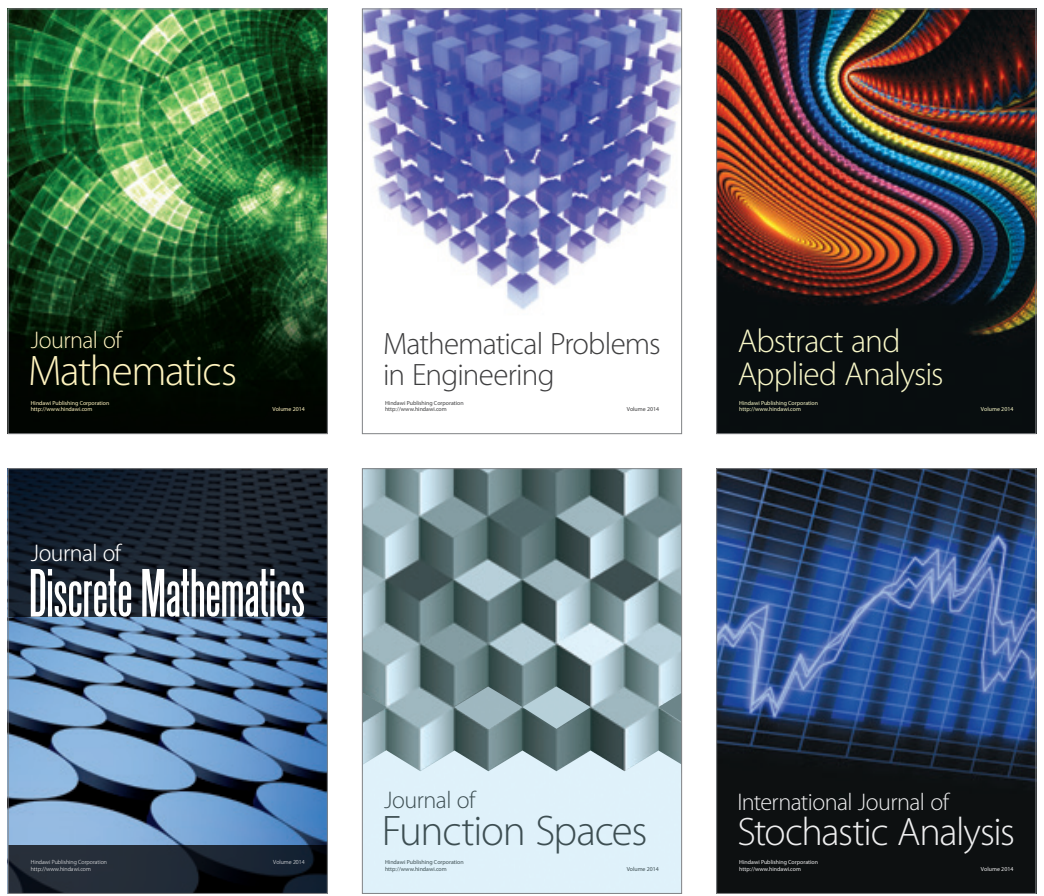

Journal of

Function Spaces

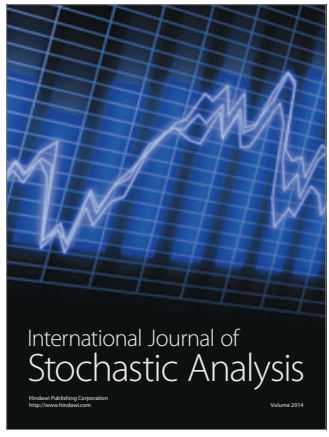

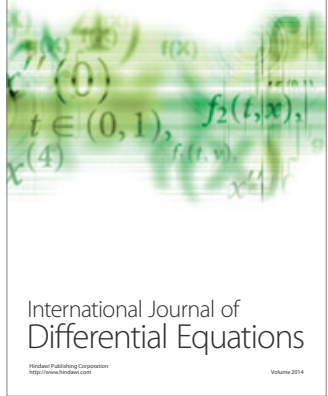
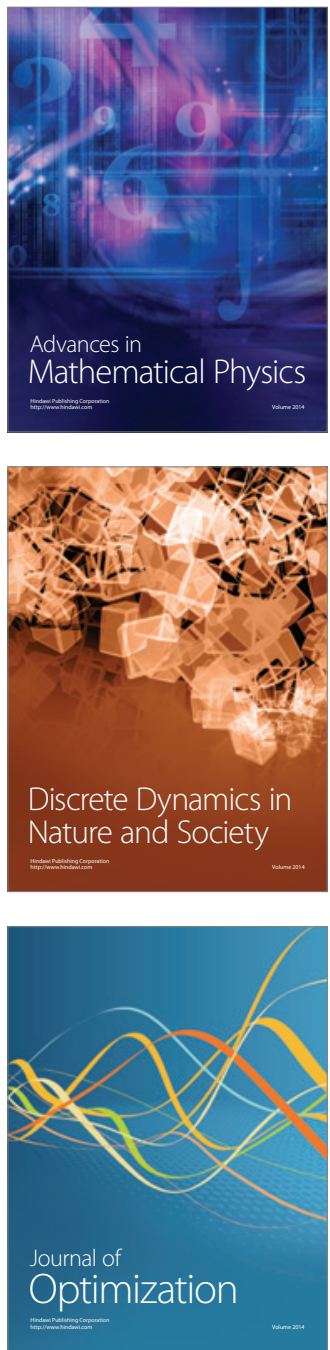